\title{
Venous thromboembolism and severe hypernatremia in a patient with lithium-induced nephrogenic diabetes insipidus and acute kidney injury: a case report
}

\author{
Young Jin Goo ${ }^{1}$, Su Hyun Song ${ }^{1}$, Oh Il Kwon ${ }^{1}$, Minah Kim ${ }^{1}$, Sang Heon Suh ${ }^{1}$, Tae Ryom $\mathrm{Oh}^{1}$, \\ Hong Sang Choi ${ }^{1}$, Eun Hui Bae ${ }^{1,2}$, Seong Kwon Ma ${ }^{1,2}$, Soo Wan Kim ${ }^{1,2}$, Chang Seong Kim ${ }^{1,2}$, \\ ${ }^{1}$ Department of Internal Medicine, Chonnam National University Hospital, Gwangju, Korea; ${ }^{2}$ Department of Internal Medicine, Chonnam National \\ University Medical School, Gwangju, Korea \\ Correspondence to: Chang Seong Kim. Department of Internal Medicine, Chonnam National University Medical School, 160, Baekseo-ro, Dong-gu, \\ Gwangju, 61469, Republic of Korea. Email: laminion@hanmail.net.
}

\begin{abstract}
We report a case of thromboembolism in a patient with hypernatremia resulting from lithiuminduced nephrogenic diabetes insipidus (NDI). A 49-year-old female patient on chronic lithium therapy due to bipolar disorder was transferred to the emergency department with signs of dehydration, altered mental status, and increased oxygen demand. She was admitted to a local psychiatric clinic first because of an exacerbation of a manic episode. When she was transferred to our clinic, her blood pressure was 130/80 $\mathrm{mmHg}$, she was tachycardic (110 beats/min), had tachypnea (24 breaths/min), normal body temperature $\left(36.5^{\circ} \mathrm{C}\right)$, and an oxygen saturation of $94 \%$ via a face mask $(10 \mathrm{~L} / \mathrm{min})$. Laboratory results showed hypertonic hypernatremia (osmolality, $363 \mathrm{mOsm} / \mathrm{kg}$; sodium, $171 \mathrm{mEq} / \mathrm{L}$ ), low urine osmolality (osmolality, $231 \mathrm{mOsm} / \mathrm{kg}$ ), and normal urine sodium (Na, $63 \mathrm{mEq} / \mathrm{L}$ ). Her serum lithium concentration was above the therapeutic range $(1.52 \mathrm{mmol} / \mathrm{L})$. An increase in cardiac markers and changes in electrocardiogram were detected; therefore, echocardiography was performed, which showed right ventricular dysfunction and small left ventricular chamber size. Computed tomography of the chest and lower extremities showed pulmonary thromboembolism (PTE) and deep venous thrombosis (DVT). She was treated with hypotonic fluid to correct hypernatremia and intravenous heparin for thromboembolism. The size of the thromboembolism decreased, and hypernatremia was corrected. She was discharged with a direct oral anticoagulant (DOAC). Here, we report a case of severe hypernatremia and venous thromboembolism in lithium-induced NDI.
\end{abstract}

Keywords: Thrombosis; hypernatremia; nephrogenic diabetes insipidus (NDI); case report

Submitted Jul 23, 2021. Accepted for publication Oct 21, 2021.

doi: 10.21037/apm-21-2025

View this article at: https://dx.doi.org/10.21037/apm-21-2025

\section{Introduction}

Hypernatremia, defined as an increase in serum sodium concentration $>145 \mathrm{mEq} / \mathrm{L}$, is a common electrolyte disturbance caused by excessive loss of water or sodium overload (1). Hypernatremia occurs frequently in hospitalized patients as an iatrogenic condition, and the most serious cause of complications is not only due to the disorder itself, but also due to inadequate treatment (2). Lithium is one of the most common therapeutic agents used to treat mood disorders. However, kidney injury can be induced by lithium, the most prevalent form being impaired urinary concentrating ability, resulting from decreased responsiveness of the distal nephron to the antidiuretic

^ ORCID: 0000-0001-8753-7641. 
action of arginine vasopressin $(3,4)$. Lithium inhibits vasopressin-stimulated cyclic adenosine monophosphate, resulting in reduced diffusion of water through water channels in the cell membrane of the collecting tubule (5). Under certain circumstances, severe hypernatremia can occur if the patient does not drink adequate water (6). Signs of dehydration include decreased skin turgor, dry oral mucosa, and tachycardia. Hypernatremia can cause central nervous system dysfunction ranging from confusion to coma (7). There are also several case reports of cerebral and systemic circulatory thrombosis associated with hypernatremia (8-11).

This report describes an unprecedented case of lifethreatening thromboembolic events involving concurrent deep venous thrombosis (DVT) and pulmonary thromboembolism (PTE) in the presence of hypernatremia induced by nephrogenic diabetes insipidus (NDI) following supratherapeutic lithium level. We present the following article in accordance with the CARE reporting checklist (available at https://apm.amegroups.com/article/ view/10.21037/apm-21-2025/rc).

\section{Case presentation}

A 49-year-old female patient was transferred to our emergency department with abnormal laboratory findings and drowsiness. The patient had a long history of bipolar disorder, which was treated with lithium carbonate for at least 10 years in addition to other antipsychotics, including quetiapine, olanzapine, and valproate. The dose of lithium prescribed lastly to the patient was $300 \mathrm{mg}$ per day. She had been admitted to a local hospital for the previous two weeks for behavioral therapy. At the time of admission to the local clinic, the patient was alert and did not show any abnormality in physical activities. Her routine laboratory examination revealed no abnormalities including renal function test. However, 5 days before transfer, her creatinine level rose from 0.8 to $1.5 \mathrm{mg} / \mathrm{dL}$. The patient was diagnosed with acute kidney injury and was given intravenous Hartmann solution for 5 days. The day before transfer, she became drowsy, and her laboratory findings showed more elevated creatinine, newly detected hypernatremia, and increased cardiac markers.

At the time of admission to our clinic, her blood pressure was $130 / 80 \mathrm{mmHg}$, heart rate was 110 beats/min, respiratory rate was 24 breaths $/ \mathrm{min}$, body temperature was $36.5^{\circ} \mathrm{C}$, and oxygen saturation was $94 \%$ via a face mask $(10 \mathrm{~L} / \mathrm{min})$. She was delirious, and physical examination showed dry mouth, dry skin, and decreased turgor. On the day of admission, her laboratory results (normal range) were as follows: white blood cell count, $12,800 / \mu \mathrm{L}(4,000-8,000 / \mu \mathrm{L})$; hemoglobin level, $11.9 \mathrm{~g} / \mathrm{dL}(12-18 \mathrm{~g} / \mathrm{dL})$; blood urea nitrogen level, $32.7 \mathrm{mg} / \mathrm{dL}(8-23 \mathrm{mg} / \mathrm{dL})$; serum creatinine level, $2.77 \mathrm{mg} / \mathrm{dL}(0.5-1.3 \mathrm{mg} / \mathrm{dL})$; serum sodium level, $171 \mathrm{mEq} / \mathrm{L}$ (136-146 mEq/L); serum osmolality, $363 \mathrm{mOsm} / \mathrm{kg}$ (280-295 mOsm/kg); serum potassium level, $4.5 \mathrm{mEq} / \mathrm{L}$ (3.5-5.1 mEq/L); chloride concentration, $144 \mathrm{mEq} / \mathrm{L}$ (98-110 mEq/L); C-reactive protein level, $2.82 \mathrm{mg} / \mathrm{dL}$ $(0-0.3 \mathrm{mg} / \mathrm{dL})$; lactate level, $1.39 \mathrm{mmol} / \mathrm{L}(0.5-2.2 \mathrm{mmol} / \mathrm{L})$; Troponin I level, $1.656 \mathrm{ng} / \mathrm{mL}(0-0.05 \mathrm{ng} / \mathrm{mL})$; and CKMB level, $7.08 \mathrm{ng} / \mathrm{mL}(0-4.87 \mathrm{ng} / \mathrm{mL})$. The prothrombin time was $13.8 \mathrm{~s}$ [international normalized ratio (INR), $1.20 \mathrm{~s}$ ], activated partial thromboplastin time (aPTT) was $27.3 \mathrm{~s}$, fibrinogen level was $184.8 \mathrm{mg} / \mathrm{dl}$, fibrinogen degeneration product level was $7.2 \mu \mathrm{g} / \mathrm{mL}$ (normal, <5), and D-dimer level was $14.38 \mathrm{mg} / \mathrm{L} \mathrm{FEU}$ (normal, <0.55). Her serum lithium concentration was $1.52 \mathrm{mmol} / \mathrm{L}$ (therapeutic interval, 1-1.2). Urinalysis showed low urine osmolality (osmolality, $231 \mathrm{mOsm} / \mathrm{kg}$ ) and normal urine sodium $(\mathrm{Na}, 63 \mathrm{mEq} / \mathrm{L})$. Electrocardiogram demonstrated inverted $\mathrm{T}$ waves in leads V2 to V6. Due to changes in electrocardiogram and elevated cardiac markers, an echocardiogram was performed, which showed a small left ventricle chamber size due to dehydration and right ventricle dysfunction. Enhanced computed tomography (CT) of the chest revealed multifocal PTE involving the main, lobar, and segmental branches of both pulmonary arteries (Figure 1A). Abdominal CT showed normal kidney size and morphology. CT venography of both lower extremities showed DVT involving the left distal femoral, popliteal, and both crural veins (Figure 1B). Brain magnetic resonance imaging showed no abnormalities associated with delirious mental changes.

For 2 weeks after admission, the patient continued to have polyuria ( $>3 \mathrm{~L} /$ day). Considering the patient's polyuria, laboratory test, history of lithium intake, and brain imaging, the patient was diagnosed with lithium-induced NDI, resulting in severe hypernatremia. She was also diagnosed with thromboembolism and acute kidney injury complications.

The patient was given hypotonic fluid, in the form of $5 \%$ dextrose to correct hypernatremic dehydration. At the same time, since there was no hypotension, thrombolysis was not performed, and anticoagulation therapy using heparin was started. Her serum lithium level dropped below the therapeutic range, as lithium was withheld. Due to persistent polyuria, thiazide $(25 \mathrm{mg})$ was added to treat 

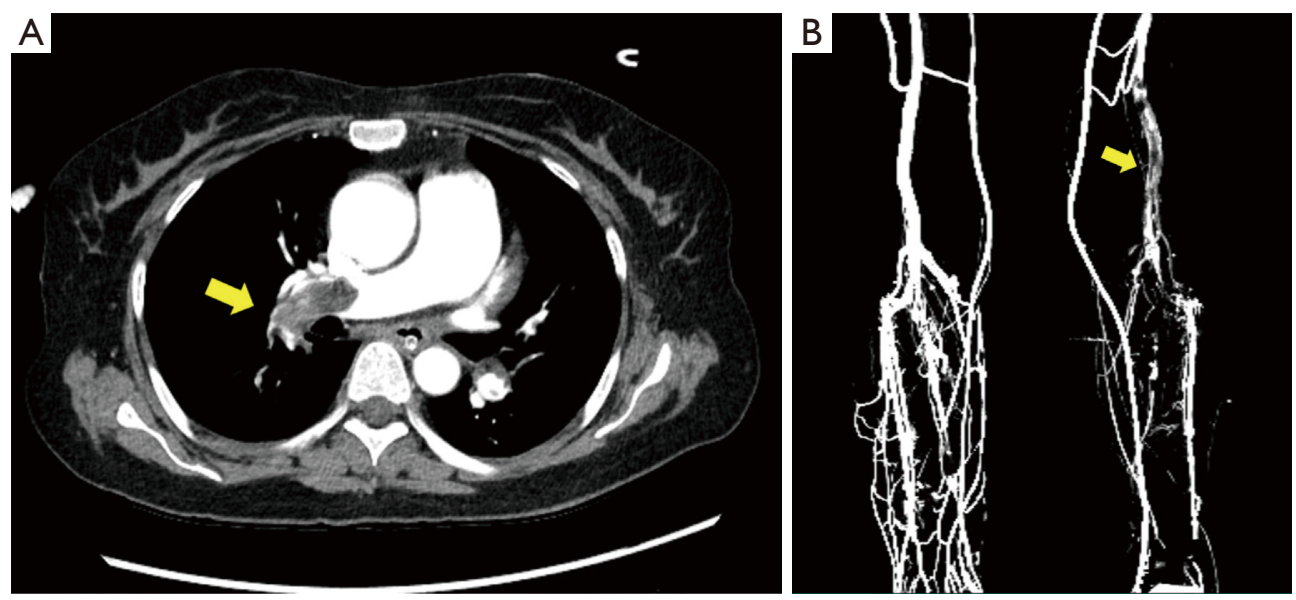

Figure 1 Computed tomography of the chest and lower extremities at the time of admission. (A) At the time of admission, enhanced computed tomography scan of the chest revealed multifocal PTE involving main, lobar, segmental branches of both pulmonary arteries (yellow arrow); (B) extremities computed tomography showed increased extent of DVT (yellow arrow). PTE, pulmonary thromboembolism; DVT, deep vein thrombosis.

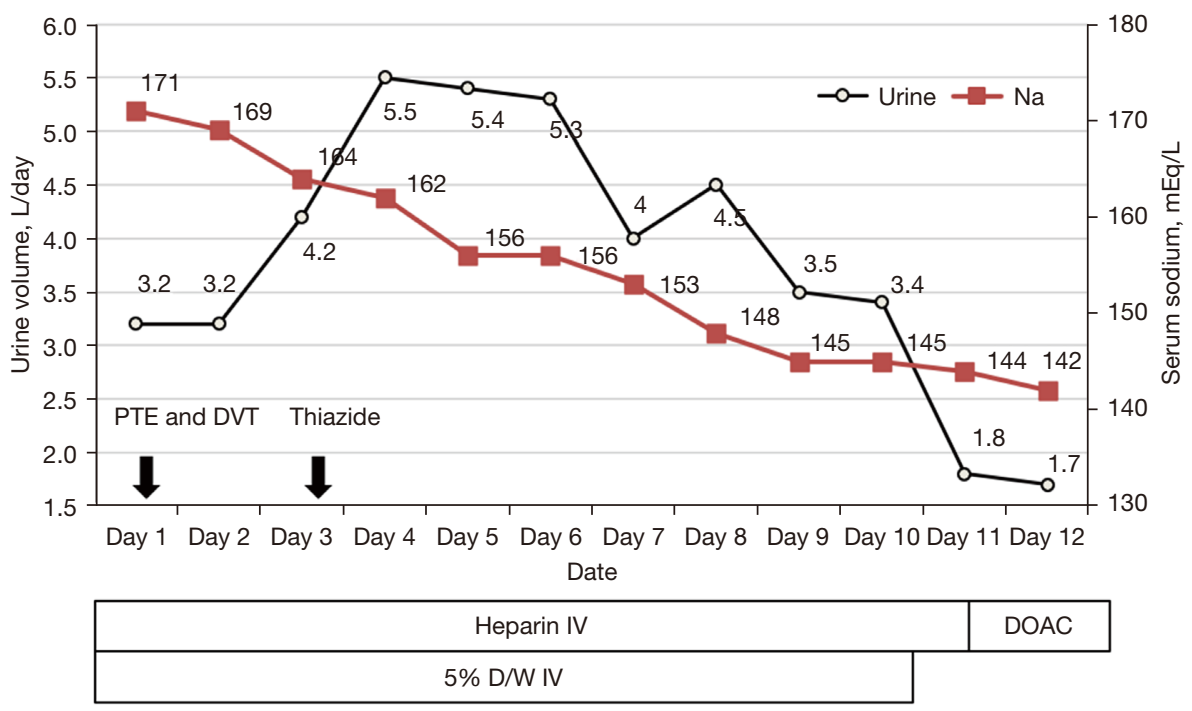

Figure 2 Timeline of the patient's clinical course showing serum sodium and urine output. Na, sodium; PTE, pulmonary thromboembolism; DVT, deep vein thrombosis; IV, intravenous; DOAC, direct oral anticoagulant.

NDI. Hypernatremia and creatinine were corrected over 10 days, and polyuria also improved (Figure 2). As her electrolytes were corrected, her mental state returned to normal.

On the $12^{\text {th }}$ day of admission, follow-up chest CT and lower extremity CT venography showed a decreased extent of PTE and DVT. Intravascular heparin was switched to direct oral anticoagulant (DOAC). The patient wanted to receive antipsychotics at the local clinic she was attending and was discharged from our hospital with edoxaban (60 mg daily), a DOAC. All procedures performed in this study were in accordance with the ethical standards of the institutional and/or national research committee(s) and with the Helsinki Declaration (as revised in 2013). Written informed consent was obtained from the patient for publication of this case report and any accompanying images. A copy of the written consent is available for review by the editorial office of this journal. 


\section{Discussion}

Here, we report a case of thromboembolism possibly caused by hypernatremia after chronic lithium therapy. The patient had polyuria, and her laboratory results demonstrated hypernatremia, normal urine sodium concentration, and decreased urine osmolality. Considering the patient's polyuria, laboratory test, history of lithium intake, and brain imaging, the patient was diagnosed with lithium-induced NDI, resulting in severe hypernatremia. Further imaging studies revealed DVT and PTE. Lithium is one of the most common therapeutic agents used to treat affective disorders and the most common cause of NDI (5). Patients with NDI drink adequate amounts of water to maintain normal tonicity in response to increased osmolality. However, under certain conditions when fluid intake is restricted, severe hypernatremia may occur (6). There are few case reports on thrombosis of both the cerebral and systemic circulation associated with hypernatremia (8-11). Kamijo et al. (10) reported a patient with dural sinus thrombosis associated with hypernatremia after long-term lithium therapy, who died of massive hemorrhagic infarction secondary to dural sinus thrombosis. Vikrant et al. (11) reported the case of a 22-year-old male patient with severe hypernatremia secondary to untreated seizure disorder complicated by DVT, who was treated with low-molecularweight heparin and oral anticoagulants, leading to complete resolution of thrombosis. Also, Elias et al. (12) revealed that dehydration is a possible cause of increasing incidence of venous thromboembolism (VTE).

In a recent study by Dmitrieva et al. (13), the relationship between the production and secretion of von Willebrand factor (vWF) and elevation of plasma sodium was tested. Human umbilical vein endothelial cells (HUVECs) in culture were exposed to hypernatremic media to test whether high $\mathrm{NaCl}$ concentrations affected the production of vWF. HUVECs maintain logarithmic growth by adapting to the elevated $\mathrm{NaCl}$ range occurring in hypernatremia, and the rate of secretion of $\mathrm{vWF}$ returns to normal by lowering $\mathrm{NaCl}$, demonstrating that the salt-dependent increase is reversible. Dmitrieva et al. investigated whether water restriction resulting in elevated serum sodium increases vWF secretion in murine endothelial cells. The researchers analyzed $v W F$ mRNA and protein in water-restricted mouse tissues and found that it significantly increased $v W F$ mRNA in the liver and lungs, as well as in some other tissues, but not to a statistically significant degree. Consequently, elevated plasma sodium increases the production and secretion of $\mathrm{vWF}$ by endothelial cells in both the human umbilical vein and mice in vivo. In addition, a high salt concentration increases the expression of tonicity-regulated transcription factor NFAT5, which attaches to the promoter of the $v W F$ gene, suggesting upregulation of $\mathrm{vWF}$, and consequently, increased coagulation and thrombosis. VTE often manifests as DVT and can be life-threatening when exacerbated by PTE (14). This pathomechanism has been studied only in vivo, and there is no case of clinical study examined the relationship between $\mathrm{vWF}$ and hypernatremia. Therefore, further studies are needed.

The D-dimer test is an exclusion tool of VTE diagnosis, which offers a measure of ongoing fibrinolysis and has a high negative predictive value. If VTE is suspected in clinical evaluation, the patient will undergo ultrasound (for DVT) or CT (for PTE) to detect possible thrombosis (15).

In conclusion, we report a rare case in which DVT with PTE was possibly caused by hypernatremia secondary to lithium-induced NDI. This case report highlights the need for prevention of dehydration and adequate hydration in patients with diabetes insipidus.

\section{Acknowledgments}

Funding: This research was supported by grants (BCRI20062, BCRI21023) from Chonnam National University Hospital Biomedical Research Institute.

\section{Footnote}

Reporting Checklist: The authors have completed the CARE reporting checklist. Available at https://apm.amegroups. com/article/view/10.21037/apm-21-2025/rc

Peer Review File: Available at https://apm.amegroups.com/ article/view/10.21037/apm-21-2025/prf

Conflicts of Interest: All authors have completed the ICMJE uniform disclosure form (available at https://apm. amegroups.com/article/view/10.21037/apm-21-2025/coif). CSK reports that this study was supported by Chonnam National University Hospital Biomedical Research Institute (BCRI20062, BCRI21023). The other authors have no conflicts of interest to declare.

Ethical Statement: The authors are accountable for all aspects of the work in ensuring that questions related to the accuracy or integrity of any part of the work are 
appropriately investigated and resolved. All procedures performed in this study were in accordance with the ethical standards of the institutional and/or national research committee(s) and with the Helsinki Declaration (as revised in 2013). Written informed consent was obtained from the patient for publication of this case report and any accompanying images. A copy of the written consent is available for review by the editorial office of this journal.

Open Access Statement: This is an Open Access article distributed in accordance with the Creative Commons Attribution-NonCommercial-NoDerivs 4.0 International License (CC BY-NC-ND 4.0), which permits the noncommercial replication and distribution of the article with the strict proviso that no changes or edits are made and the original work is properly cited (including links to both the formal publication through the relevant DOI and the license). See: https://creativecommons.org/licenses/by-nc-nd/4.0/.

\section{References}

1. Adrogué HJ, Madias NE. Hypernatremia. N Engl J Med 2000;342:1493-9.

2. Palevsky PM, Bhagrath R, Greenberg A. Hypernatremia in hospitalized patients. Ann Intern Med 1996;124:197-203.

3. Bedford JJ, Weggery S, Ellis G, et al. Lithium-induced nephrogenic diabetes insipidus: renal effects of amiloride. Clin J Am Soc Nephrol 2008;3:1324-31.

4. Mukhopadhyay D, Gokulkrishnan L, Mohanaruban K. Lithium-induced nephrogenic diabetes insipidus in older people. Age Ageing 2001;30:347-50.

5. Boton R, Gaviria M, Batlle DC. Prevalence, pathogenesis, and treatment of renal dysfunction associated with chronic lithium therapy. Am J Kidney Dis 1987;10:329-45.

Cite this article as: Goo YJ, Song SH, Kwon OI, Kim M, Suh SH, Oh TR, Choi HS, Bae EH, Ma SK, Kim SW, Kim CS. Venous thromboembolism and severe hypernatremia in a patient with lithium-induced nephrogenic diabetes insipidus and acute kidney injury: a case report. Ann Palliat Med 2022;11(8):2756-2760. doi: 10.21037/apm-21-2025
6. Hyperosmolar coma due to lithium-induced diabetes insipidus. Lancet 1995;346:413-7.

7. Chassagne P, Druesne L, Capet C, et al. Clinical presentation of hypernatremia in elderly patients: a case control study. J Am Geriatr Soc 2006;54:1225-30.

8. Bhattacharya D, Angurana SK, Sundaram V, et al. Cerebral Sinovenous Thrombosis due to Hypernatremic Dehydration in a Neonate. Neurol India 2021;69:164-6.

9. Conde MP, Rodríguez MÁ, López JM, et al. Thrombosis secondary to acute hypernatraemia after liver hydatid cyst surgery. Blood Coagul Fibrinolysis 2015;26:695-8.

10. Kamijo Y, Soma K, Hamanaka S, et al. Dural sinus thrombosis with severe hypernatremia developing in a patient on long-term lithium therapy. J Toxicol Clin Toxicol 2003;41:359-62.

11. Vikrant S, Pandey D, Raina R, et al. Deep vein thrombosis complicating severe hypernatremia, rhabdomyolysis, and acute renal failure in a patient with untreated seizure disorder. Clin Exp Nephrol 2007;11:88-91.

12. Elias S, Hoffman R, Saharov G, et al. Dehydration as a Possible Cause of Monthly Variation in the Incidence of Venous Thromboembolism. Clin Appl Thromb Hemost 2016;22:569-74.

13. Dmitrieva NI, Burg MB. Secretion of von Willebrand factor by endothelial cells links sodium to hypercoagulability and thrombosis. Proc Natl Acad Sci U S A 2014;111:6485-90.

14. Wendelboe AM, Campbell J, McCumber M, et al. The design and implementation of a new surveillance system for venous thromboembolism using combined active and passive methods. Am Heart J 2015;170:447-54.e18.

15. Di Nisio M, van Es N, Büller HR. Deep vein thrombosis and pulmonary embolism. Lancet 2016;388:3060-73. 